\title{
Mumps outbreak in the Federation of Bosnia and Herzegovina with large cohorts of susceptibles and genetically diverse strains of genotype $G$, Bosnia and Herzegovina, December 2010 to September 2012
}

\author{
M Hukic (mirsadahukic@yahoo.com)1, A Hajdarpasic ${ }^{2}$, J Ravlija ${ }^{3}$, Z Ler ${ }^{3}$, R Baljic ${ }^{4}$, A Dedeic Ljubovic ${ }^{1}$, A Moro ${ }^{1}$, I Salimović-Besic $^{1}$, \\ A Sausy5, C P Muller5, J M Hübschen 5 \\ 1. Institute of Clinical Microbiology, Clinical Centre University of Sarajevo, Sarajevo, Bosnia and Herzegovina \\ 2. Centre for Genetics, Faculty of Medicine, University of Sarajevo, Laboratory for Molecular Medicine, Sarajevo, Bosnia and \\ Herzegovina \\ 3. Institute of Public Health of Federation Bosnia and Herzegovina, Sarajevo, Bosnia and Herzegovina \\ 4. Clinic for Infectious Diseases, Clinical Centre University of Sarajevo, Sarajevo, Bosnia and Herzegovina \\ 5. Institute of Immunology, World Health Organization European Regional Reference Laboratory for Measles and Rubella, Centre \\ de Recherche Public de la Santé /Laboratoire National de Santé, Luxembourg, Luxembourg
}

Citation style for this article:

Hukic M, Hajdarpasic A, Ravlija J, Ler Z, Baljic R, Dedeic Ljubovic A, Moro A, Salimović-Besic I, Sausy A, Muller CP, Hübschen JM. Mumps outbreak in the Federation of Bosnia and Herzegovina with large cohorts of susceptibles and genetically diverse strains of genotype G, Bosnia and Herzegovina, December 2010 to September 2012. Euro Surveill. 2014;19(33):pii=20879. Available online: http://www.eurosurveillance.org/ViewArticle.aspx?Articleld=20879

Article submitted on 28 January 2014 / published on 21 August 2014

A mumps outbreak reported from the Federation of Bosnia and Herzegovina involved 7,895 cases between December 2010 and September 2012. This was the largest outbreak in the country since the introduction of the measles, mumps and rubella vaccine in 1980. The highest disease incidence was found among 15 to 19 year-olds. About $39 \%(3,050 / 7,895)$ of cases reported to be unvaccinated; the vaccination status of $31 \%(2,426 / 7,895)$ was unknown. A seroprevalence study among 150 asymptomatic contacts to mumps cases showed that about one third (45/150) were susceptible to mumps. Among 105 clinically suspected mumps patients hospitalised at the Clinical Centre of the University of Sarajevo, orchitis $(60 \%$ of all males: 51/85) and meningitis ( $9 \%: 9 / 105)$ were the most common complications. Among 57 outbreak sequences obtained for the small hydrophobic gene, eight different variants of genotype $G$ viruses were identified. The outbreak affected mainly age groups comprising individuals who were not vaccinated during or after the Bosnian war, as well as cantons with single dose immunisation policies until 2001. In addition to issues related to vaccination of individuals, differential responses to vaccines and vaccine strains, waning of antibodies and potentially also the genetically diverse variants of genotype $\mathrm{G}$ may have compounded the size and duration of the outbreak. Our report emphasizes the need for supplementary immunisation programmes in particular for adolescents and young adults.

\section{Introduction}

Mumps is an infection with acute onset of unilateral or bilateral self-limited swelling of the parotid or other salivary glands, which lasts at least two days.
The incubation period ranges from 12 to 25 days after exposure to the virus. Transmission from one person to another mostly occurs before and within five days of parotitis onset [1]. The disease is caused by mumps virus (MuV) and can be associated with complications such as aseptic meningitis, encephalitis, hearing loss, orchitis, oophoritis, mastitis or pancreatitis [1]. There is no specific treatment and vaccination is the only effective measure to prevent the disease. The presence of specific immunoglobulin $M(\operatorname{Ig} M)$ in the serum confirms recent mumps infection. Reverse transcription-polymerase chain reaction (RT-PCR) is becoming increasingly popular for laboratory investigation of clinically suspected cases and provides also genotype information of circulating strains [1]. Currently, 12 different genotypes of mumps virus are recognised and genotype $\mathrm{G}$ seems to be the most prevalent genotype in Europe [2].

The combined measles, mumps and rubella (MMR) vaccine is in use in Bosnia and Herzegovina (B\&H) since 1980 [3,4]. From 1980 to 1992 one dose of vaccine was given at 12 months of age and if this opportunity was missed, before the age of 14 years. The Republic of Srpska (RS) and some cantons of the second main entity of $B \& H$, the Federation of Bosnia and Herzegovina (FB\&H) (Bosnian Podrinje, Central Bosnia, Herzegovina-Neretva, Sarajevo, Tuzla, UnaSana, Zenica-Doboj) continued to use the one-dose schedule until 2001. The remaining cantons (Canton 10, Posavina, West Herzegovina), two of which border Croatia, adopted in 1992 a two-dose schedule with the first dose given at 12 months and the second dose at seven years and no later than 14 years of age. In such 
cantons, individuals born between 1981 and 1992 were given an opportunity for a second dose of vaccine. Since 2001, the two-dose MMR vaccination schedule is implemented throughout B\&H [5], whereby cantons, which had a single dose schedule until 2001, offer two doses to individuals born from 2001 onwards.

The Public Health Institute of FB\&H manages the national immunisation programme in FB\&H and each canton is responsible for its implementation at the level of local health centres. Mumps is one of ten infectious diseases against which vaccination is compulsory and free of charge in FB\&H. The immunisation status is checked by looking at the vaccination records when children enter kindergarten, when they start primary school and again during periodic revisions in preparation of the yearly immunisation plan and/or supplementary immunisation activities. Incompletely immunised children are vaccinated in catch-up campaigns.

The war between 1992 and 1995 disrupted MMR vaccination across the entire territory of $\mathrm{B} \& \mathrm{H}$ and deficiencies in the programme persisted up to several years after the war [3]. For instance, periodic shortages of vaccine supply and interruptions in the cold chain were reported. In addition, many refugees did not have any medical records. Before the introduction of vaccination against mumps, outbreaks occurred every three to four years and later every seven to eight years [4]. Between December 2010 and September 2012 a higher disease incidence with peaks in April 2011 and January 2012 was observed. This report describes this epidemic and investigates its causes.

\section{Methods}

Any patient with acute onset of unilateral or bilateral tender, self-limited swelling of the parotid or other salivary gland, lasting two or more days and without other apparent cause was considered a clinically suspected mumps case [6]. Suspected mumps cases are normally reported by medical practitioners to the Institute for Public Health of FB\&H, which investigates outbreaks and reports to the Ministry of Health. Epidemiological data of 7,895 clinically suspected mumps cases reported between December 2010 and September 2012 were collected by the Institute for Public Health. The vaccination status of patients less than 18 years-old was checked in their medical records kept at the local health centre. For older patients the immunisation status was either checked in their medical records or self-reported.

\section{Serological study}

Serum was collected from 221 individuals between four and 64 years of age (mean: 21 years) who were clinically suspected mumps cases $(n=71)$ or asymptomatic contacts to mumps cases $(n=150)$ from the cantons of Sarajevo, Central Bosnia and Zenica-Doboj. All sera were tested with the Siemens Enzygnost Anti-Parotitis Virus kits for mumps-specific IgG and IgM antibodies.
Hospitalisation and complications

Between April 2011 and September 2012, 105 clinically suspected mumps cases from Central Bosnia and Sarajevo cantons were hospitalised at the Clinical Centre of the University of Sarajevo. Throat swabs were collected from all 105 patients and their medical records were checked.

\section{Molecular and phylogenetic analysis of the mumps virus outbreak strains}

RNA was extracted from the throat swabs of the 105 patients hospitalised at the Clinical Centre of the University of Sarajevo using the QIAamp Viral RNA Mini kit (Qiagen, Germany) according to the manufacturer's instructions.

For reverse transcription, $5 \mu \mathrm{l}$ of RNA and random hexamers were used in a total volume of $20 \mu \mathrm{l}$. PCRs were performed to amplify a genetic region comprising the small hydrophobic (SH) gene using previously described primers [7]. The genetic sequence was either obtained by one PCR (first PCR) or by two consecutive PCRs, whereby the first PCR was followed by a nested PCR. Starting material included $1 \mu \mathrm{l}$ of CDNA for the first PCR, or $1 \mu \mathrm{l}$ of the first PCR-product, for the nested PCR. The amplification steps consisted of an initial incubation for 5 minutes at $94^{\circ} \mathrm{C}$, followed by 39 cycles of $94^{\circ} \mathrm{C}$ for 30 seconds, 56 or $52^{\circ} \mathrm{C}$ (first PCR) and 58 or $52^{\circ} \mathrm{C}$ (nested PCR) for 1 minute and $72^{\circ} \mathrm{C}$ for 1 minute, followed by a final extension at $72^{\circ} \mathrm{C}$ for 10 minutes. PCR products were analysed in a $1.5 \%$ agarose gel and only samples negative after the first PCR were further amplified by nested PCR. PCR-positive samples were sequenced using nested primers and the BigDye Terminator v3.1 Cycle Sequencing Kit (Applied Biosystems, USA).

Sequences were analysed by SeqScape Software v2.5 (Applied Biosystems, USA), BioEdit version 7.0.9.0 [8] and molecular evolutionary genetics analysis (MEGA)4 software [9]. Neighbour-joining phylogenetic trees based on the Kimura 2-parameter model were constructed using 316 nucleotide (nt) sequences comprising the complete $\mathrm{SH}$ gene. The recommended set of reference sequences [2] and some identical or similar sequences obtained by basic local alignment search tool (BLAST) were included in the phylogenetic analysis. Nt sequences of the $\mathrm{SH}$ gene were translated into the corresponding amino acid sequences with BioEdit. Statistical tests for significance were done using SPSS 15.0 (IBM, USA).

\section{Results}

\section{Outbreak description}

In the period from December 2010 to September 2012, a mumps outbreak including 7,895 cases was observed in FB\&H. The outbreak consisted of two distinct epidemic waves, with one epidemic peak observed in April 2011 ( $n=1,240$ cases) and another in January 2012 $(n=509)$ (Figure 1). 
Number of mumps cases, by age group, in an outbreak presenting two epidemic waves in the Federation of Bosnia and Herzegovina, Bosnia and Herzegovina, December 2010-September 2012 ( $n=7,895)$

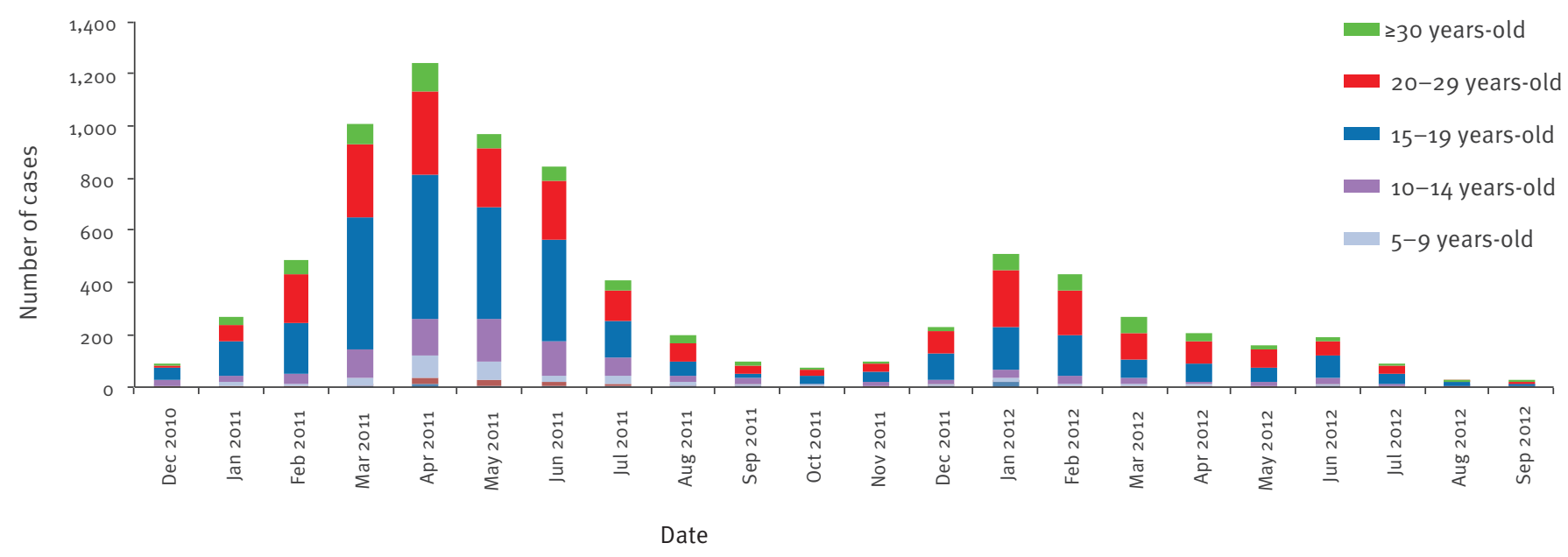

Overall, the majority of cases reported (82\%: $6,481 / 7,895)$ were located in three cantons: Central Bosnia ( $n=2,434$ cases), Zenica-Doboj $(n=2,215)$ and Sarajevo $(n=1,832)$. These cantons had a one dose vaccination schedule until 2001. In contrast, Canton 10, and the cantons of Posavina and West Herzegovina, all, which had a two dose schedule since 1992, included only a total of 59 reported cases.

During the first wave of the outbreak, between December 2010 and the end of October 2011, 5,677 mumps cases were reported, mainly in the cantons of Central Bosnia, Zenica-Doboj, Sarajevo and Herzegovina-Neretva $(n=5,534$ cases in total for the four cantons) [3]. The second epidemic wave from November 2011 to September 2012, accounted for an additional 2,218 cases. During the second wave, cases continued to occur in the four previously most-affected cantons, but several hundred cases were also reported from Una-Sana $(n=355)$ and Tuzla $(n=450)$ cantons. Una-Sana and Tuzla cantons, which reported only sporadic cases during the first wave in 2011, observed the highest disease incidence at the beginning of 2012, during the second epidemic wave.

Considering the whole outbreak, the age of the cases ranged from less than one year to 64 years with a median age of 19 years. The age group comprising 15 to 19 year-olds was most affected during the first epidemic wave in 2011, while the highest case numbers were observed in 20 to 29 year-olds during the second wave (Figure 1). For the entire outbreak, nearly $82 \%$ $(6,455 / 7,895)$ of the cases were older than 14 years (Figures 1 and 2). More males (63\%: 5,005/7,895) than females were affected overall and in each age group, except for the one to four year-olds (Figure 2). Among the 20 to 29 year-old cases there were even more than twice as many males than females (Figure 2).
Mumps cases reported during the outbreak were mostly unvaccinated (39\%: 3,050/7,895) or had an unknown vaccination status (31\%: 2,426/7,895). The other cases had been vaccinated with either one dose (15\%: $1,217 / 7,895)$ or with two doses of mumps-containing vaccine (15\%: 1,202/7,895).

\section{Serology results}

Among 71 patients with clinical symptoms consistent with mumps, 57 (80\%) were IgM positive and IgG negative, two (3\%) were positive for both IgM and IgG antibodies and 12 (17\%) were only IgG positive. Among the 150 contacts without clinical signs or symptoms, five (3\%) were IgM positive and IgG negative, 100 (67\%) were only IgG positive and 45 (30\%) were negative for both IgM and IgG antibodies. A positive serological test for mumps-specific IgM antibodies, with or without the presence of IgG, confirms recent infection. The presence of mumps-specific IgG antibodies indicates previous contact with mumps virus either by vaccination or natural infection.

\section{Hospitalisation and complications}

The median age of the 105 hospitalised patients was 20 years with a range of three to 64 years (Figure 3 ). The great majority were male ( $81 \%: 85 / 105)$. Similar to the overall cohort of reported cases, most of the hospitalised patients were unvaccinated (34\%: 36/105) or had an unknown vaccination status (36\%: 38/105) (Table). A total of $28 \%(29 / 105)$ were vaccinated with two doses of mumps containing vaccine and $2 \%(2 / 105)$ were vaccinated with one dose only (Table). The medical records documented serious complications such as orchitis (60\% of all males: $51 / 85)$, meningitis ( $9 \%: 9 / 105)$ and orchitis and meningitis ( $2 \%$ of all males: $2 / 85$ ) in hospitalised patients (Table and Figure 3 ). There was no statistically significant difference in the prevalence of complications between vaccinated and unvaccinated 


\section{FIGURE 4}

Phylogenetic analysis of 57 mumps virus sequences of genotype G obtained during a mumps outbreak in the Federation of Bosnia and Herzegovina, Bosnia and Herzegovina, December 2010-September 2012

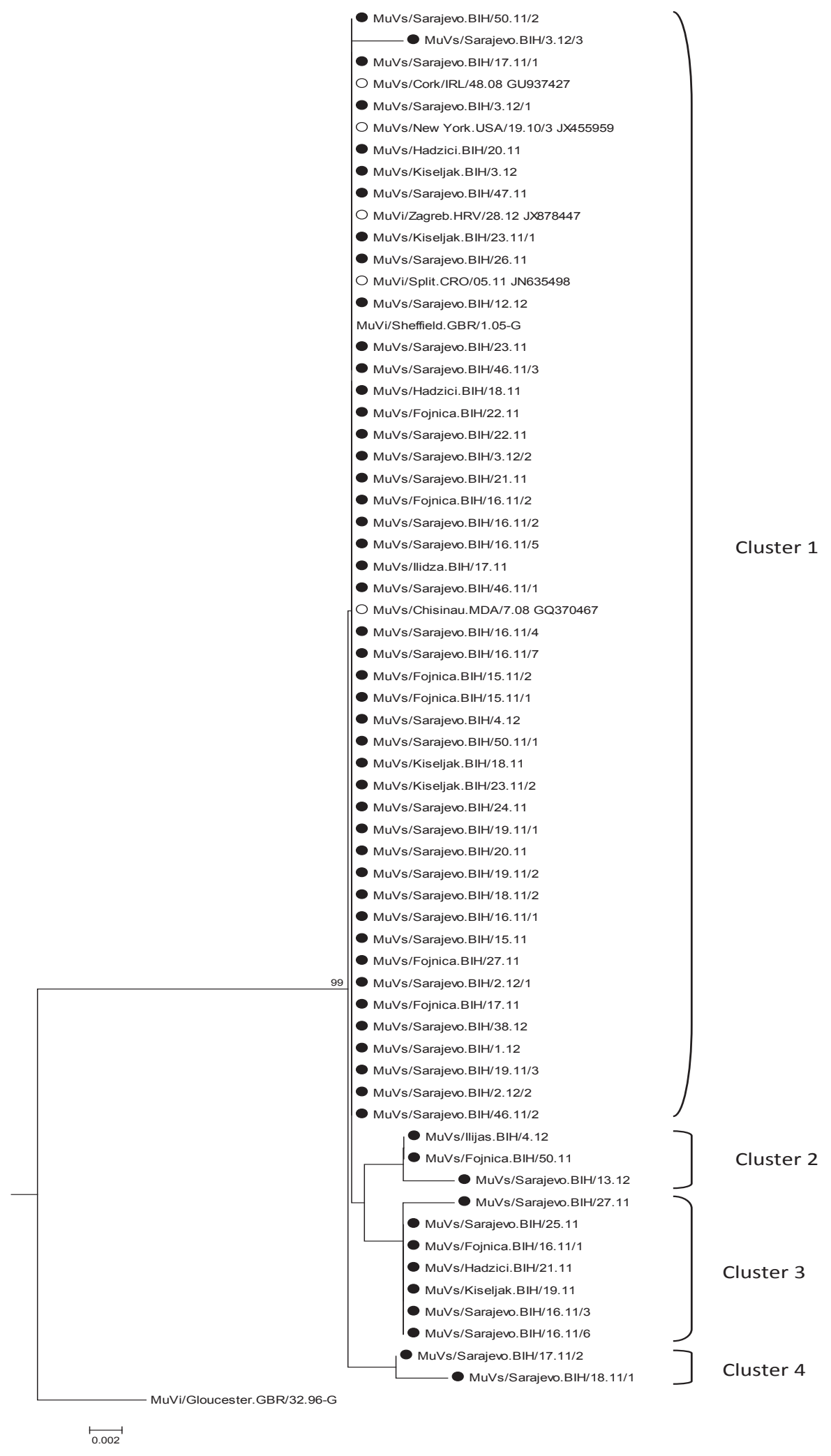

The Figure focuses on the genotype $\mathrm{G}$ cluster obtained within a larger phylogenetic tree, which was constructed with the neighbour-joining and Kimura 2 parameter methods, based on 316 nucleotide-long sequences comprising the SH gene, that were obtained in this study or in GenBank, and all World Health Organization reference sequences [2]. The sequences obtained during the outbreak are marked with full dots and the closest basic local alignment search tool (BLAST) fits among recently detected sequences are marked with open dots. 


\section{FIGURE 2}

Number of mumps cases by age and sex in an outbreak in the Federation of Bosnia and Herzegovina, Bosnia and Herzegovina, December 2010-September 2012 (n=7,895)

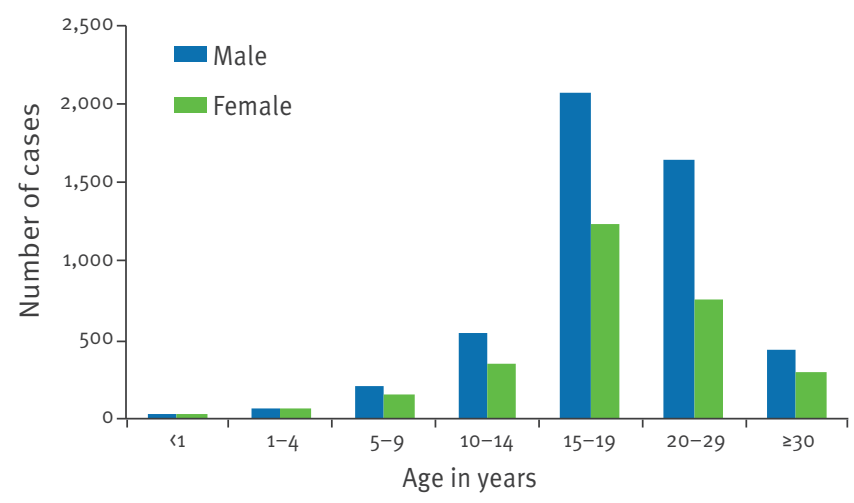

patients $(p=0.723)$ or patients with unknown vaccination status $(p=0.171)$ (Table).

Table. Characteristics of mumps patients hospitalised at the Clinical Centre of the University of Sarajevo during a mumps outbreak in the Federation of Bosnia and Herzegovina, Bosnia and Herzegovina, December 2010-September $2012(n=105)$

\section{Molecular characterisation of the mumps} strains detected during the outbreak

A total of 58 of 105 throat swabs collected from suspected mumps patients were positive for MuV by PCR. Sequence information comprising the complete $\mathrm{SH}$ gene was obtained from 57 samples (GenBank accession numbers: HF912174 to HF912230). Eight different genotype $G$ sequence variants forming four clusters were detected (Figure 4). Cluster 1 comprised the main outbreak variant (represented by 44 sequences), as well as an additional single sequence (MuVs/Sarajevo. $\mathrm{BIH} / 3.12 / 3$ ) which differed by one nt to the 44 others. A second cluster (cluster 2) of three sequences was found later during the outbreak (end of 2011 and in 2012); the sequence detected at the latest time point differed by a single nt from the other two. Cluster 3 comprised six identical sequences collected during week 16 to 25 (mid-April to second half of June) in 2011 and a sequence differing by one nt collected in week 27 (beginning of July). Cluster 4 comprised only two sequences differing by one nt from each other collected in weeks 17 and 18 (end of April to beginning of May) of 2011 (Figure 4). Overall, the outbreak sequences did not vary from each other by more than four nt. The maximum number of changes observed compared to the main variant was two nt. The main outbreak variant was identical to strains from Croatia (MuVi/Split.CRO/05.11, MuVi/Zagreb.HRV/28.12), the United States (US) (e.g. MuVs/New_York.USA/19.10/3), Ireland (MuVs/Cork/IRL/48.08) and Moldova (MuVs/ Chisinau.MDA/7.08). No sequences identical to any of the other seven variants were found in GenBank.
Some of the genetically diverse variants had predicted amino acid substitutions in the SH protein: all sequences in cluster 3 had Leu2oMet in the predicted $\mathrm{SH}$ protein; the two sequences in cluster 4 showed His40Tyr and sequence MuVs/Sarajevo.BIH/18.11/1 in addition Phe49Ser; sequence MuVs/Sarajevo. $\mathrm{BIH} / 3.12 / 3$ in cluster 1 had a predicted His50Tyr change.

The 13 patients infected with genetically diverse virus variants showed no symptoms different from the patients infected with the main strain. Variant strains were found in five different locations of FB\&H (Sarajevo, Ilijas, Fojnica, Hadzici and Kiseljak).

\section{Discussion}

Between December 2010 and September 2012, 7,895 mumps cases were registered in FB\&H and about 7,700 additional cases in RS, leading to approximately 15,600 cases across B\&H. This was by far the largest mumps outbreak in the country since the introduction of the vaccine in 1980 [3] and it was also one of the largest outbreaks reported from Europe since the period between 2008 and 2009 [10].

The outbreak affected mainly regions of $\mathrm{B} \& \mathrm{H}$ with a single dose schedule until 2001, which is in line with the down to $60 \%$ long-term population-based effectiveness of a single dose of mumps vaccine [11]. During the 1992 to 1995 war and several years after, immunisation activities were irregular [3] with large cohorts of susceptibles, especially in regions where only a single vaccination opportunity was provided. This also explains why most patients involved in the recent mumps outbreak ( $72 \%: 5,710 / 7,895$ ) belonged to the age groups 15 to 19 and 20 to 29 years (born 1981-1997) and why the majority of the patients (69\%: $5,476 / 7,895$ ) reported to be unvaccinated or had an unknown vaccination status. The breakdown of community immunity as a result of young adults moving on to new school or work environments may have compounded the incidence in this age group. A high mumps incidence among adolescents and young adults who were unvaccinated or received only a single dose has been reported from several other European countries [10,12-14].

Also waning of protective levels of antibodies $[10,15]$ even after two doses may have played a role. Since mumps outbreaks seem to occur even in highly vaccinated communities, a third dose of mumps-containing vaccine as a booster later in life is currently under discussion [14-17]. Whether the robustness and persistence of the immune response to the various vaccine strains used in B\&H during the past years (Institute for Immunology, Zagreb, Croatia (L-Zagreb strain, 19801999); GlaxoSmithKline Beecham, Belgium (RIT 4385 strain,1999-2012); Aventis Pasteur, France (Urabe strain, 2007 only) [4]) differed as was observed previously $[11,18]$ deserves further attention. 
Characteristics of mumps patients hospitalised at the Clinical Centre of the University of Sarajevo during a mumps outbreak in the Federation of Bosnia and Herzegovina, Bosnia and Herzegovina, December 2010-September 2012 $(n=105)$

\begin{tabular}{|c|c|c|c|c|c|}
\hline \multirow[b]{2}{*}{ Vaccination status } & \multirow[b]{2}{*}{ Number of patients } & \multicolumn{4}{|c|}{ Complications } \\
\hline & & $\begin{array}{c}\text { Orchitis } \\
\mathrm{n}(\%)\end{array}$ & $\begin{array}{c}\text { Meningitis } \\
\mathrm{n}(\%)\end{array}$ & $\begin{array}{l}\text { Orchitis and } \\
\text { meningitis } n(\%)\end{array}$ & $\begin{array}{c}\text { No complications } \\
\mathrm{n}(\%)\end{array}$ \\
\hline Vaccinated (2 doses) & 29 & $16(55)$ & $4(14)$ & $1(3)$ & $8(28)$ \\
\hline Vaccinated (1 dose) & 2 & $1(50)$ & $\mathrm{o}(0)$ & $\mathrm{O}(\mathrm{o})$ & $1(50)$ \\
\hline Unvaccinated & 36 & $20(56)$ & $1(3)$ & $1(3)$ & $14(39)$ \\
\hline Unknown & 38 & $14(37)$ & $4(11)$ & o (o) & $20(53)$ \\
\hline Total & 105 & $51(49)$ & $9(9)$ & $2(2)$ & $43(41)$ \\
\hline
\end{tabular}

In response to the outbreak, all children less than 14 years of age who had received less than two doses of MMR vaccine were vaccinated, mumps cases were isolated, some schools with large numbers of cases were closed and the citizens were alerted via the media. However, the fact that each of the ten cantons of FB\&H has its own health system, in addition to the anti-vaccination propaganda during the past few years $[19,20]$ probably contributed to the overall rather weak and slow response to the outbreak.

Currently no mumps seroprevalence data are available for $\mathrm{FB} \& \mathrm{H}$. The investigation of sera from a small number $(n=150)$ of asymptomatic mumps patient contacts during the recent outbreak showed that about one third did not have specific IgG antibodies and were considered to be susceptible. A thorough seroprevalence study to identify main groups of susceptibles for targeted supplementary immunisation activities is warranted. Among the 71 clinically suspected mumps patients, 12 (17\%) had IgG and no IgM antibodies, indicating that at least some of these patients may have been reinfected with mumps virus or infected after vaccination. In such cases virus detection should be attempted $[21,22]$, but no samples besides serum were available from these patients.

The typical male complications may explain why more male patients in the 15 to 29 year age bracket were recorded. In fact, orchitis with or without meningitis was the most common complication in hospitalised patients. In contrast to a recently published study [21], we did not find any significant difference in disease severity between vaccinated and unvaccinated hospitalised patients. This may be due to low numbers

\section{FIGURE 3}

Complications observed among mumps patients hospitalised at the Clinical Centre of the University of Sarajevo according to age, mumps outbreak in the Federation of Bosnia and Herzegovina, Bosnia and Herzegovina, December 2010-September $2012(n=105)$

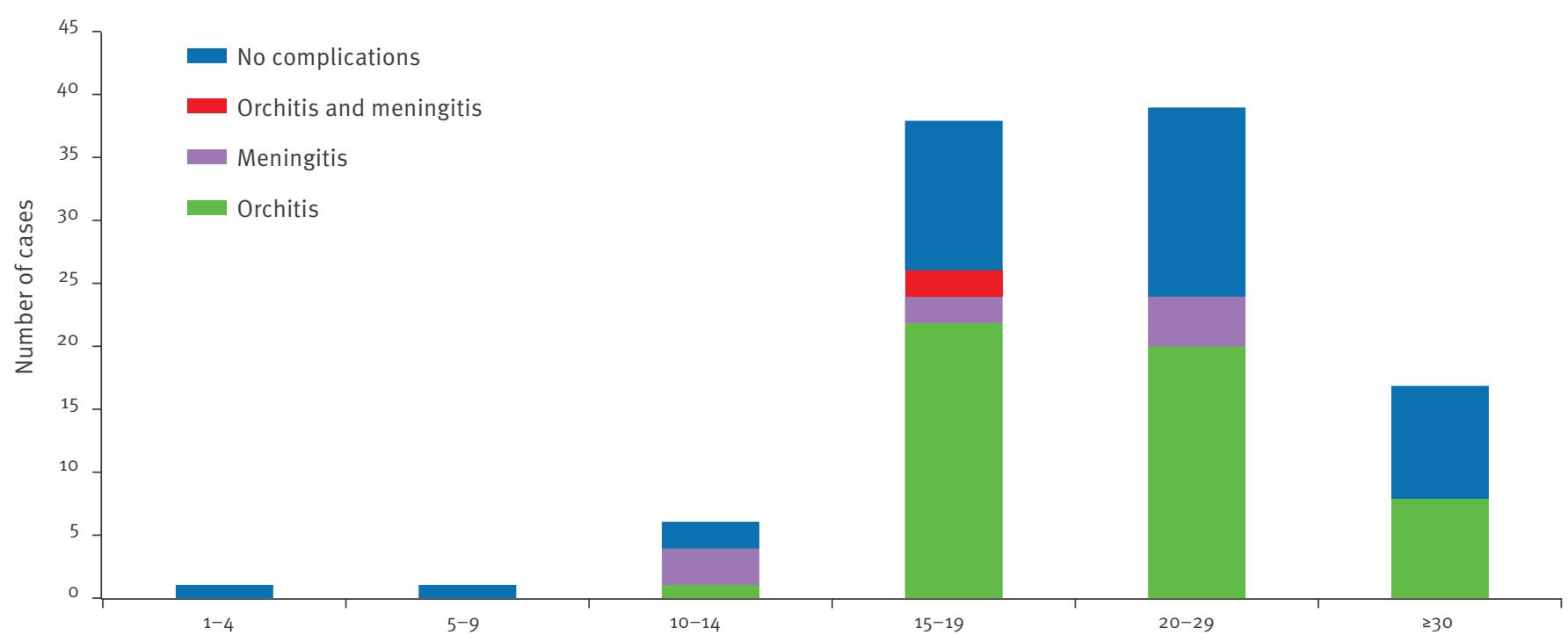

Age groups in years 
of patients in each category, but also to confounding effects of vaccine quality during and after the war.

SH gene sequences from 57 patients belonged to genotype $G$ and eight different sequence variants were found. The main outbreak variant was identical to strains detected in the US in 2010 and in Croatia in 2011 and 2012. As nothing is known about the genetic variants of mumps virus present in FB\&H before the outbreak, we can only speculate whether the virus was endemic in the country or whether it was introduced from the US or a European source, perhaps related to the earlier Ireland and Moldova 2008 cases.

Seven sequence variants were different from any of the sequences on GenBank. Since only 57 sequences from only two cantons were obtained while approximately 15,600 mumps cases were reported from throughout $B \& H$, it is likely that the real sequence diversity is underestimated. Nevertheless, this diversity is already considerably higher than during a one-year outbreak in the US with 3,500 cases where 221 sequences differed by no more than a single nt [21]. Since at least cluster 1,3 and 4 sequences were present already by the beginning of 2011 and genetically diverse strains were found in five different locations, the most probable scenario is that different variants were present in $\mathrm{B} \& \mathrm{H}$ already before the outbreak and/or correspond to multiple independent transmission chains. Some variation seems to have been generated during the epidemic since within clusters 2, 3 and 4 the strain collected at the latest time point was always the most diverse.

The differing strain from cluster 1 and all sequences from clusters 3 and 4 showed changes in the predicted amino acid sequence of the $\mathrm{SH}$ protein. Of note, the cluster 3 strains had a leucine to methionine substitution in position 20 of the predicted SH protein, which could potentially result in an $\mathrm{N}$-terminal truncation. As the $\mathrm{SH}$ protein has been reported to inhibit tumour necrosis factor alpha-mediated apoptosis [23-25], it is conceivable that a truncated SH protein may have lost the ability to inhibit programmed cell death leading potentially to more severe clinical manifestations. In fact, six of the seven patients with the predicted leucine to methionine substitution in position 20 were hospitalised due to disease complications ( 4 had orchitis, 1 had orchitis and meningitis and 1 had meningitis). Further investigations are clearly warranted to elucidate the significance of the methionine substitution as well as the other predicted amino acid mutations.

It has been suggested that the gradual antigenic evolution of mumps viruses may undermine vaccine effectiveness [26]. A recent study showed indeed that the genotype A strain Jeryl-Lynn induced less neutralising antibodies against the common genotype $G$ virus than against the vaccine strain [27]. The 13 patients who were infected with the genetically diverse variants in our study were between 18 and 43 years-old (mean: 25.2 years) and most of them reported that they had received two doses of vaccine (54\%: $7 / 13)$ or that the vaccination history was unknown (31\%: $4 / 13)$. Thus it is conceivable that waning of antibodies, vaccine quality issues, intensive exposure [21] or potentially an even lower neutralisation capacity against the present genotype $\mathrm{G}$ variants played a role in the outbreak.

In conclusion, we identified failures to vaccinate during and after the war and single dose immunisation policies in some cantons as important causes for the large and persistent mumps outbreak. Those may have been compounded by differential responses to vaccines and vaccine strains, waning of antibodies and potentially by the genetically diverse variants of genotype G. Molecular analysis of the mumps strains involved, revealed a level of diversity in the virus suggestive of several transmission chains, possibly as a result of long-term endemic circulation of mumps viruses in FB\&H. Our study identified large cohorts of susceptibles and emphasises the need for supplementary immunisation activities in particular among adolescents and young adults who have received less than two vaccine doses.

\section{Acknowledgements}

The authors are grateful to all doctors and epidemiologists who were involved in the study. In addition, they thank the Luxembourg Ministry of Foreign Affairs for financially supporting the work done in Luxembourg.

\section{Conflict of interest}

None declared.

Authors' contributions

MH was involved in the design of the study, drafted the article, contributed to the recruitment of study participants and management of their personal data, as well as participated in the analysis and interpretation of the results, the initiation of the study and the revision of the manuscript. AH was involved in interpretation of the results and the writing of the manuscript. JR was involved in the statistical analysis of epidemiological data. ZL was involved in the statistical analysis of epidemiological data. RB was involved in clinical data analysis. ADL contributed to the recruitment of study participants and the management of their personal data. AM performed clinical analysis and serological experimental work. ISB contributed to the recruitment of study participants and the management of their personal data. AS did all the molecular biology investigations. CPM was involved in the data interpretation and the revision of the manuscript. JMH contributed to the conception of the study, the interpretation of the results and the writing of the manuscript.

\section{References}

1. Parker Fiebelkorn A, Barskey A, Hickman C, Bellini W. Manual for the Surveillance of Vaccine-Preventable Diseases. 5th Edition. Atlanta, GA: US Department of Health and Human Services, CDC; 2012. Chapter 9, Mumps. Available from: http:// www.cdc.gov/vaccines/pubs/surv-manual/chptog-mumps.html

2. World Health Organization. Mumps virus nomenclature update: 2012. Wkly Epidemiol Rec. 2012;87(22):217-24. 
3. Hukic M, Ravlija J, Dedeic Ljubovic A, Moro A, Arapcic S, Muller $\mathrm{CP}$, et al. Ongoing large mumps outbreak in the Federation of Bosnia and Herzegovina, Bosnia and Herzegovina, December 2010 to July 2011. Euro Surveill. 2011;16(35):pii=19959

4. Institute of Public Health, Federation of Bosnia and Herzegovina, Sarajevo, Bosnia and Herzegovina. Epidemiological bulletins of the Institute of Public Health, 1997-2009; vol. 16-28.

5. Karakas S, Tandir S. Epidemiologija. [Epidemilogy]. Univerzitet u Zenici, Zdravstveni fakultet. Travnik: Print-GS; 2009. 231-34. Bosnian.

6. World Health Organization (WHO). WHO-recommended surveillance standard of mumps. Geneva: WHO. [Accessed 10 Jan 2013]. Available from: http://www.who.int/immunization/ monitoring_surveillance/burden/vpd/surveillance_type/ passive/mumps_standards/en/

7. Jin L, Beard S, Brown DW. Genetic heterogeneity of mumps virus in the United Kingdom: identification of two new genotypes. J Infect Dis. 1999;180(3):829-33. http://dx.doi. org/10.1086/314957

8. Hall TA. BioEdit: a user-friendly biological sequence alignment editor and analysis program for Windows 95/98/NT. Nucl Acids Symp Ser. 1999;41:95-8.

9. Tamura K, Dudley J, Nei M, Kumar S. MEGA4: Molecular Evolutionary Genetics Analysis (MEGA) software version 4.0. Mol Biol Evol. 2007;24(8):1596-9. http://dx.doi.org/10.1093/ molbev/msmog2

10. Kuzmanovska G, Polozhani A, Mikik V, Stavridis K, Aleksoski B, Cvetanovska Z, et al. Mumps outbreak in the former Yugoslav Republic of Macedonia, January 2008-June 2009: epidemiology and control measures. Euro Surveill. 2010;15(23):pii=19586.

11. World Health Organization. Mumps virus vaccines. Wkly Epidemiol Rec. 2007;82(7):51-60.

12. Karagiannis I, van Lier A, van Binnendijk R, Ruijs $H$, Ruijs H, Fanoy E, et al. Mumps in a community with low vaccination coverage in the Netherlands. Euro Surveill. 2008;13(24): pii=18901.

13. Rajcevic S, Seguljev Z, Petrovic V, Medic S, Nedelijkovic J, Milosevic V, et al. Ongoing mumps outbreak in Novi Sad, the autonomous province of Vojvodina, Serbia, January to April 2012. Euro Surveill. 2012;17(19): $\mathrm{pii}=20169$.

14. Walker J, Huc S, Sinka K, Tissington A, Oates K. Ongoing outbreak of mumps infection in Oban, Scotland, November 2010 to January 2011. Euro Surveill. 2011;16(8): $\mathrm{pii}=19803$.

15. Eriksen J, Davidkin I, Kafatos G, Andrews N, Barbara C, Cohen D, et al. Seroepidemiology of mumps in Europe (1996-2008): why do outbreaks occur in highly vaccinated populations? Epidemiol Infect. 2013: 651-66. http://dx.doi.org/10.1017/ So950268812001136

16. Anis E, Grotto I, Moerman L, Warshavsky B, Slater PE, Lev B. Mumps outbreak in Israel's highly vaccinated society: are two doses enough? Epidemiol Infect. 2012;140(3):439-46. http:// dx.doi.org/10.1017/S095026881100063X

17. Marin M, Quinlisk P, Shimabukuro T, Sawhney C, Brown $C$, Lebaron CW. Mumps vaccination coverage and vaccine effectiveness in a large outbreak among college students-lowa, 2006. Vaccine. 2008;26(29-30):3601-7. http://dx.doi. org/10.1016/j.vaccine.2008.04.075

18. Schwarz NG, Bernard H, Melnic A, Bucov V, Caterinciuc N, an der Heiden $M$, et al. Mumps outbreak in the Republic of Moldova, 2007-2008. Pediatr Infect Dis J. 2010;29(8):703-6. http://dx.doi.org/10.1097/INF.ob013e3181d743df

19. Udruženje roditelja teško bolesne djece u BiH. [Association of parents of seriously ill children in BiH]. [Accessed 19 Aug 2014]. Bosnian. Available from: http://www.roditeljstvo.com/ tagovi/udruzenje-roditelja-tesko-bolesne-djece-u-bih

20. Udruženje roditelja teško bolesne djece u BiH pozvalo roditelje Bojkot vakcinacije protiv hepatitisa B. [Association of Parents of seriously ill children in Bosnia and Herzegovina called on parents boycott of vaccination against hepatitis B]. [Accessed 19 Aug 2014]. Bosnian. Available from: http://www.federalna. ba/bhs/vijest/37081/poziv-roditeljima-iz-udruzenja-roditeljatesko-bolesne-djece-u-bih

21. Barskey AE, Schulte C, Rosen JB, Handschur EF, RauschPhung E, Doll MK, et al. Mumps outbreak in Orthodox Jewish communities in the United States. N Engl J Med. 2012;367(18):1704-13. http://dx.doi.org/10.1056/ NEJMoa1202865

22. Yoshida N, Fujino M, Miyata A, Nagai T, Kamada M, Sakiyama $\mathrm{H}$, et al. Mumps virus reinfection is not a rare event confirmed by reverse transcription loop-mediated isothermal amplification. J Med Virol. 2008;80(3):517-23. http://dx.doi. org/10.1002/jmv.21106

23. Wilson RL, Fuentes SM, Wang P, Taddeo EC, Klatt A, Henderson AJ, et al. Function of small hydrophobic proteins of paramyxovirus. J Virol. 2006;80(4):1700-9. http://dx.doi. org/10.1128/JVI.80.4.1700-1709.2006

24. Woznik M, Rodner C, Lemon K, Rima B, Mankertz A, Finsterbusch T. Mumps virus small hydrophobic protein targets ataxin-1 ubiquitin-like interacting protein (ubiquilin 4). J Gen Virol. 2010;91(Pt 11):2773-81. http://dx.doi.org/10.1099/ vir.0.024638-0

25. Xu P, Li Z, Sun D, Lin Y, Wu J, Rota PA, et al. Rescue of wild-type mumps virus from a strain associated with recent outbreaks helps to define the role of the SH ORF in the pathogenesis of mumps virus. Virology. 2011;417(1):126-36. ttp://dx.doi. org/10.1016/j.virol.2011.05.003

26. Santak M, Lang-Balija M, Ivancic-Jelecki J, Kosutic-Gulija T, Ljubin-Sternak S, Forcic D. Antigenic differences between vaccine and circulating wild-type mumps viruses decreases neutralization capacity of vaccine-induced antibodies. Epidemiol Infect. 2013;141(6):1298-309. http://dx.doi. org/10.1017/So950268812001896

27. Rubin SA, Qi L, Audet SA, Sullivan B, Carbone KM, Bellini WJ, et al. Antibody induced by immunization with the Jeryl Lynn mumps vaccine strain effectively neutralizes a heterologous wild-type mumps virus associated with a large outbreak. J Infect Dis. 2008;198(4):508-15. http://dx.doi. org/10.1086/590115 